\title{
Macroalgae and Activated Sludge Microbes in Treatment of Crepe Cotton Effluent
}

\author{
Muttu Pandian P., Matheswaran M., Vanitha S., Sivapragasam C., \\ Naresh K. Sharma
}

\begin{abstract}
Crepe cotton bandages (textile fabrics) are common household kit in the medical first aid boxes and are globally used in pharmaceutical and health care units to offer heat, insulation and support in many medical situations. Southern Tamilnadu comprises of more than 150 crepe bandage textile units and exports tonnes of crepe cottons. Many units are operated on continuous basis and therefore the amount of wastewater generated and its treatment is of critical importance. Unlike typical textile effluent, crepe cotton processing wastewater do not contain dyes, but significant proportions of caustic soda, soda ash, bleaching agents and COD. This paper discusses the effluent treatment of crepe cotton processing units using mixed cultures of macroalgae and activated sludge microbes. There are very few studies comparing the performance of activated sludge and macro algae in wastewater treatment. Fresh water macroalgae was collected from a nearby pond and activated sludge was collected from the aeration basin of domestic wastewater treatment plant. Crepe cotton processing effluent had significant concentrations of COD, TDS, TSS and was highly alkaline. The COD removal efficiency of about $73.8 \%$ and $99 \%$ was obtained for macroalgae and activated sludge microbes respectively. COD removal was quick in activated sludge while macroalgae cultures took $144 \mathrm{~h}$ to remove $275 \mathrm{mg} / \mathrm{L}$ of COD. This study shows that activated sludge microbes are quick to adapt in uptake of organics from crepe cotton effluent when compared to macroalgal sp, further studies will provide insights on generating bioenergy from algal species grown in crepe cotton effluent for sustained plant operation.
\end{abstract}

Keywords: Crepe cotton processing wastewater, Macroalgae, Activated sludge, Textile effluent, Nutrients removal

\section{INTRODUCTION}

India stands third major exporter of global cotton with a value of $\$ 15$ billion following China and European Union and is predicted to expand rapidly (Ghaly et al., 2014). There are 2324 textile industries in the country consisting of composite mills and semi composite processing units. Tamilnadu, Gujarat and Punjab have large number of textile units mounting to $81 \%$ of total textile industries in the country.

Revised Manuscript Received on December 15, 2019.

* Correspondence Author

Muttupandian P., Chemical Engineering Department, National Institute of Technology Tiruchirappalli, Tamilnadu, INDIA. Email: mutadike7@gmail.com

Matheswaran M., Chemical Engineering Department, National Institute of Technology Tiruchirappalli, Tamilnadu, INDIA. Email: matheswaran@nitt.edu

Vanitha S., Civil Engineering, Kalasalingam Academy of Research and Education, Tamilnadu, INDIA. Email: svanithacivil@gmail.com

Sivapragasam C., Civil Engineering, Kalasalingam Academy of Research and Education, Tamilnadu, INDIA. Email: sivapragasam@klu.ac.in

Naresh K. Sharma*, Biotechnology, Kalasalingam Academy of Research and Education, Tamilnadu, INDIA, Email: naresh@klu.ac.in

Tamilnadu tops the chart with 741 textile plants (CPCB, 2007) and consists of many surgical cotton industries and the cotton bandages units; there is a large sum of exports of cotton products from here. Crepe cotton fabrics are globally used in pharmaceutical and health care units to offer heat, insulate and support in many medical situations. Crepe cotton bandages are also being used as most common household kit in the medical first aid boxes. Crepe cotton textile materials are processed in following steps: knitting griege fabric, keiring, bleaching, mercerization, printing and finishing. Generally, crepe cotton units do not use dyeing agents and the water discharged from these processing units are devoid of dye compounds. Babu et al., (2007) has shown that the cotton textile processing industry has the most harmful effects on environment and the water consumption typically varies from $40-65 \mathrm{~kg}$ per cloth. The effluent properties such as toxicity, carcinogenic characteristics, etc. are also higher and it's marked as one of the most polluting sector (Kyung et al., 2015). A large amount of water is consumed during the desizing and kiering processes, which are also the main sources of dissolved solids, suspended solids, COD, BOD, ammonia and sulphate contaminations.

A study by Sivakumar et al., (2011) showed the inadequacy of many textile effluent treatment plants to meet the discharge limits set by IS (201:2009). Their findings revealed that textile bleaching industries at Karur, Tamil Nadu, could cause severe pollution problems since the parameters measured have values above the tolerable limits compared to the world health organization (WHO) standards (Sivakumar et al., 2011). Similarly, Patel et al., (2013) showed that the effluent treatment plant from clusters of textile industries in Gujarat had low performance efficiency especially with respect to dissolved solids, metals and organics. The main reasons for plant failure are due to presence of excess ions (evident from the high conductivity of untreated effluent), low BOD:COD ratio (toxic to micro-organisms in secondary treatment), high metal concentration and different operating conditions than that of the designed values. In a recent study, Sonaje and Chougule, (2015) showed that huge quantities of chemical agents $(\mathrm{NaOH}-2 \%, \mathrm{Na} 2 \mathrm{CO} 3-1 \%$, Wetting agent, Vegetable Oil, Sodium Silicate, etc.,) are added in the desizing, bleaching and kiering steps of textile processing to increase the texture and whiteness of cotton fabrics. This approach results in excess of BOD, COD, dissolved solids and metallic wastes in the effluent. (Pengyi Cui et al., 2011). This effluent is highly basic in nature since it undergoes detergents and soda wash (Tamilarasan et al., 2017).

The current biological wastewater treatment methods are extensively based on bacterial sludge which cannot be effectively used as biofuels, 
feedstocks or as nutrients supplements. Macro and Microalgae are suitable alternative organisms which can utilize the $\mathrm{CO}_{2}$ produced from the degradation of organic matter and will also consume certain nutrients such as $\mathrm{NO}_{3}$, $\mathrm{NO}_{2}$ and $\mathrm{PO}_{4}{ }^{2-}$ that are discharged along with treated wastewater. Apart from efficient degradation rates, algal biomass will lead to the production of commercially important compounds from wastewater such as biofuels, feedstocks, nutrient supplements and secondary metabolites with medicinal properties (Borines et al., 2013). There are very few studies comparing the performance of activated sludge microbes and macro algae for wastewater treatment. This study therefore, compares the removal rates and performance of macroalgae and activated sludge in treatment of crepe cotton effluent.

\section{METHODOLOGY}

\section{A. Wastewater sampling and characterization} Rajapalayam, Virudhunagar district, Tamilnadu, India. The collected sample was stored at $4^{\circ} \mathrm{C}$ until analysis. The initial characteristics of crepe cotton wastewater such as $\mathrm{pH}$, Electrical conductivity, Total Suspended Solid (TSS), Total Dissolved Solids (TDS), Chemical Oxygen Demand (COD), were analyzed as per in APHA [Eaton et al., 2005]. Table 1 comprises the physicochemical characterization of crepe cotton wastewater.

\section{B. GROWTH MEDIUM}

2.2.1. Modified chu-13 Medium (MCM) for macroalgae cultivation

Modified chu medium (MCM) was prepared for the growth and batch studies of Macroalgae cultures. The medium consists of nitrate, sulphate, phosphate, chloride and citrate salts. The composition of Modified Chu-13 medium [Chu et al., 1942] is mentioned in Table 2. The contents were autoclaved at $121^{\circ} \mathrm{C}$ for $30 \mathrm{~min}$, which dissolves the trace elements. After the preparation of the medium, the $\mathrm{pH}$ was adjusted to 7.0 .

\subsubsection{Minimal Salt Medium (MSM) for activated sludge cultivation}

The Miniam Salt Medium (MSM) consists of majorly sulphate, chloride, phosphate and traces of iodide salts. The composition of Minimal media (Flores et al., 2003) is listed out in Table 3 . The contents were autoclaved at $121^{\circ} \mathrm{C}$ for 30 min, which dissolves the trace elements. After the preparation of the medium, the $\mathrm{pH}$ was adjusted to 7.0. Trace element solution consisted of $\mathrm{FeCl}_{2} .4 \mathrm{H}_{2} \mathrm{O}(1.22 \mathrm{~g} / \mathrm{L}), \mathrm{MnCl}_{2} .4 \mathrm{H} 2 \mathrm{O}$ $(4.09 \mathrm{~g} / \mathrm{L}), \mathrm{CoCl}_{2} .6 \mathrm{H} 2 \mathrm{O}(0.927 \mathrm{~g} / \mathrm{L}), \mathrm{ZnCl}_{2}(0.37 \mathrm{~g} / \mathrm{L}), \mathrm{CuCl}_{2}$ $(0.61 \mathrm{~g} / \mathrm{L}), \mathrm{NaMoO}_{4} \cdot 2 \mathrm{H}_{2} \mathrm{O}(0.579 \mathrm{~g} / \mathrm{L}), \mathrm{H}_{3} \mathrm{BO}_{3}(0.16 \mathrm{~g} / \mathrm{L}), \mathrm{KI}$ $(0.148 \mathrm{~g} / \mathrm{L}), \mathrm{NiCl}_{6} 6 \mathrm{H}_{2} \mathrm{O}(0.067 \mathrm{~g} / \mathrm{L})$, and EDTA Na $\mathrm{N}_{2} \cdot 4 \mathrm{H}_{2} \mathrm{O}$ $(6.5 \mathrm{~g} / \mathrm{L})$ (Flores et al., 2003). The $\mathrm{pH}$ was maintained at $7+0.2$ using $\mathrm{HCl}$ or $\mathrm{NaOH}$.

\section{BATCH STUDIES AND ANALYSIS}

All the batch studies were conducted separately for the macroalgae and activated sludge cultures without any $\mathrm{pH}$ control $(\mathrm{pH}$ remained in the range of 7.5-8.8). For each concentration, duplicate experiments were performed under the same condition and average values are reported. Each
The crepe cotton wastewater was collected from Chatrapatti,

experiment was carried out for a period until the system reached a steady state. Abiotic controls were also maintained and monitored during the experiments. All biodegradation experiments were performed in $500 \mathrm{~mL}$ Erlenmeyer flask containing $100 \mathrm{~mL}$ of MSM inoculated with suitable cultures. Upon incubation of the flasks at $30^{\circ} \mathrm{C}$ under agitation condition $(150 \mathrm{rpm})$, samples were withdrawn at regular time intervals, centrifuged (6708 g for $5 \mathrm{~min}$ ) and analyzed for COD, nitrate, phosphate and Ammonium concentrations. The batch experiments were conducted once with duplicates and average values reported.

Table. 1. Characteristics of crepe cotton wastewater.

\begin{tabular}{lll}
\hline Sl. No. & Parameter & Values \\
\hline 1 & COD $(\mathrm{mg} / \mathrm{L})$ & 3657 \\
2 & TSS $(\mathrm{mg} / \mathrm{L})$ & 5500 \\
3 & TDS $(\mathrm{ppm})$ & 2700 \\
4 & $\mathrm{pH}$ & 11.33 \\
5 & Conductivity $(\mathrm{mS})$ & 7.2 \\
\hline
\end{tabular}

Table 2. Modified Chu-13 Medium for macroalgae cultivation

\begin{tabular}{|l|l|}
\hline Stock solution & Amount (g/L) \\
\hline Potassium nitrate & 400 \\
\hline Potassium phosphate & 80 \\
\hline Calcium Chloride & 107 \\
\hline Magnesium sulphate & 200 \\
\hline Ferric citrate & 20 \\
\hline Trace solution & $1 \mathrm{ml}$ \\
\hline
\end{tabular}

Table 3. Minimal Salt Medium (MSM) for activated sludge microbial cultivation

\begin{tabular}{|l|l|}
\hline Stock solution & Amount (g/L) \\
\hline Ammonium sulphate & 0.3125 \\
\hline Manganese sulphate & 0.00934 \\
\hline Calcium Chloride & 0.1191 \\
\hline Magnesium sulphate & 0.1329 \\
\hline Dipotassium phosphate & 2.627 \\
\hline Monopotassium phosphate & 1.436 \\
\hline Trace solution & \\
\hline
\end{tabular}

\section{RESULT AND DISCUSSION}

\section{A. COD Removal using Macroalgae and activated sludge microbes}

It is well known that the biomass from municipal wastewater treatment plants contain microorganisms capable of biodegrading various types of organic compounds. The activated sludge microbes could therefore adapt to the organics present in crepe cotton effluent and quickly degrade the COD (4 days) in comparison to macroalgae which brought down the COD from $275 \mathrm{mg} / \mathrm{L}$ to not detectable levels in 12 days. 


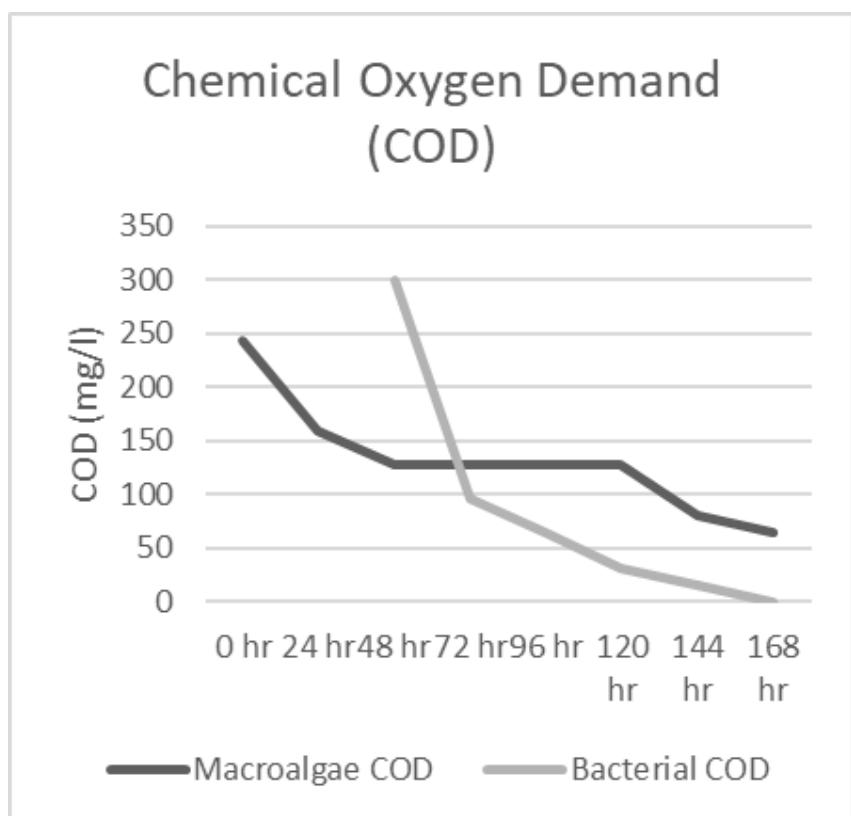

Fig. 1: COD removal using Macroalgae and activated sludge microbes from crepe cotton processing wastewater

The $\mathrm{pH}$ changed to alkaline (8.6) using macroalgae cultures while acidic $\mathrm{pH}$ of 6.1 was observed at the end of activated sludge batch experiments (Table 4.0). The COD removal efficiency was recorded about $73.8 \%$ within 12 days in macroalgal cultures while $100 \%$ removal was observed in activated sludge microbes in 8 days (Fig. 1). The shift to acidic and alkaline conditions due to activated sludge microbes and macroalgal metabolism has been observed (Myra et al., 2013).

\section{Nutrient Uptake by macroalgae and activated sludge} microbes

The sample was tested for nutrient utilization by monitoring the concentration of ammonia, nitrate and phosphate reductions during the batch studies. It is well known that microbes in activated sludge utilize ammonium as nitrogen source and oxidize to nitrate and nitrite ions. An insignificant reduction in phosphate ions was observed in activated sludge microbes

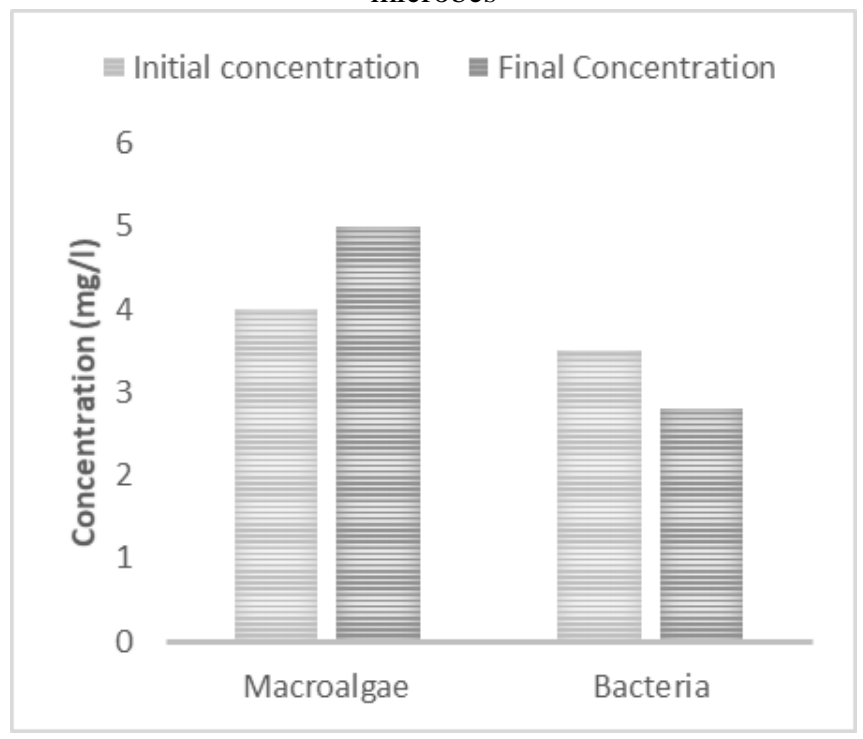

(Fig. 2).

Table. 4. pH change during batch degradation studies of crepe cotton effluent

\begin{tabular}{|l|l|l|}
\hline Culture & $\begin{array}{l}\mathbf{p H} \\
\text { (at start) }\end{array}$ & $\begin{array}{l}\mathbf{p H} \\
\text { (at end) }\end{array}$ \\
\hline Macroalgae & $7.0 \pm 0.2$ & $8.6 \pm 0.2$ \\
\hline Activated sludge & $7.0 \pm 0.2$ & $6.1 \pm 0.2$ \\
\hline
\end{tabular}

Fig. 2: Phosphate utilization by Macroalgae and activated sludge microbes from crepe cotton processing wastewater Macroalgal cultures utilized nitrates as nitrogen source for algal growth in contrast to activated sludge microbes which generated nitrates as end products of ammonium oxidation (Fig 3 and 4). There was no significant utilization of ammonium ions by macroalgal cultures, while activated sludge microbes significantly utilized ammonium for cell growth.

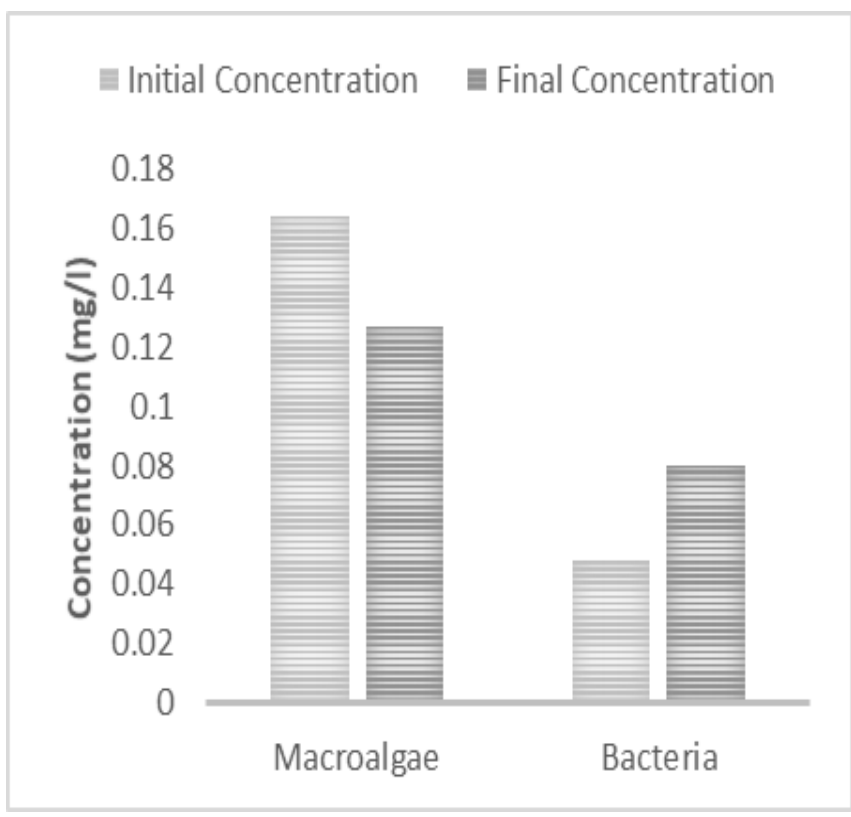

Fig. 3: Nitrate utilization by Macroalgae and activated sludge microbes from crepe cotton processing wastewater

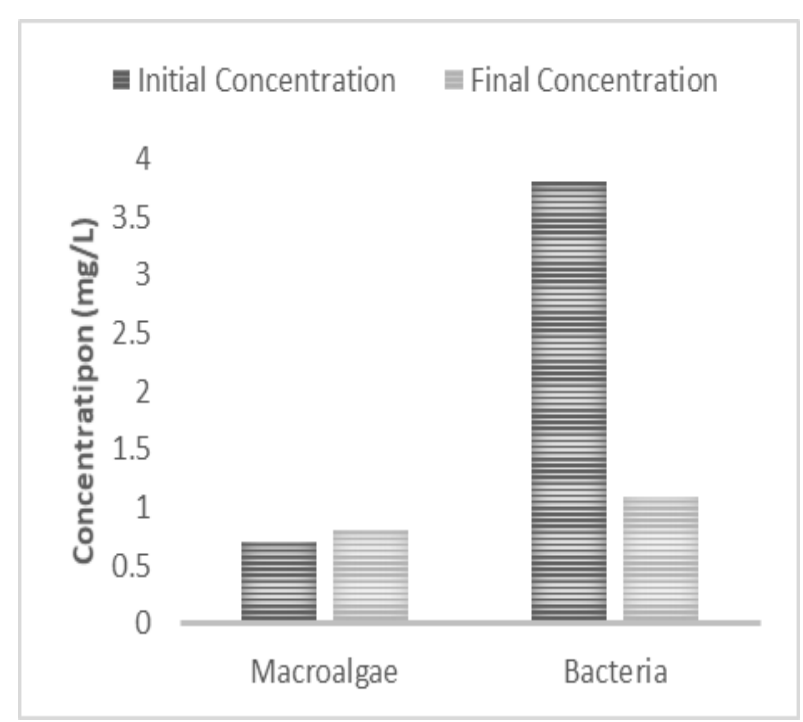

Fig. 4: Ammonia utilization by Macroalgae and activated sludge microbes from crepe cotton processing wastewater 


\section{Macroalgae and Activated Sludge Microbes in Treatment of Crepe Cotton Effluent}

Macroalgae have been shown to assimilate the organics present in the crepe cotton effluent for its growth and metabolism although the adaptation rate was much slower in comparison to activated sludge microbes. Phosphate and ammonium ions were largely unutilized by the macroalgae cultures, whereas there was significant uptake of nitrates by the macroalgal cultures as nitrogen source. Macroalgae could be harvested from the treated effluent quite easily compared to micro algal based wastewater treatment though their growth rates are slower compared to bacterial and micro algal based treatment systems.

\section{CONCLUSION}

The present study explains the removal of chemical components from the crepe cotton processing wastewater and nutrient utilization using macroalgae and activated sludge microbes. It was observed that activated sludge microbes were more effective than macroalgae in the removal and also in the utilization of ammonia at a higher rate. Though the initial degradation rates of macroalgae were slow compared to activated sludge, macroalgae based treatment could be less costly and produce biofuel and feedstock. Further studies on biofuel production and extraction of secondary metabolites could help to develop sustainable methods of crepe cotton effluent treatment.

\section{ACKNOWLEDGMENT}

The authors acknowledge the financial support for this research from Department of Science and Technology (DST) under Teachers Associateship for Research Excellence (TARE) scheme (DST/TAR/2018/000818).

\section{REFERENCES}

[1] Ghaly, R Ananthashankar, M Alhattab and VV Ramakrishnan. (2014). Production, Characterization and Treatment of Textile Effluents: A Critical Review. J ChemEng Process Technol 2014, 5:1

[2] Central Pollution Control Board (2007). Ministry of Environment and Forests. www.cpcb.nic.in

[3] Kyung-Won Jung, Min-Jin Hwang, Dae-Seon Park, Kyu-Hong Ahn, Combining fluidized metal-impregnated granular activated carbon in three-dimensional electrocoagulation system: Feasibility and optimization test of color and COD removal from real cotton textile wastewater, Separation and Purification Technology 146 (2015) $154-167$.

[4] Sivakumar K K., C. Balamurugan, D. Ramakrishnan and LeenaHebsiBhai. (2011). Assessment studies on wastewater pollution by textile dyeing and bleaching industries at karur, tamilnadu. Rasayan J Chem. 4 (2), 264-269.

[5] Patel, S., Rajor, A., Jain, B. P., \& Patel, P. (2013). Performance Evaluation of Effluent Treatment Plant of Textile Wet Processing Industry : A Case Study of Narol Textile Cluster, Ahmedabad, Gujarat, 2(4), 290-296.

[6] Sonaje N.P and M.B. Chougule (2015). Wastewater Recycling In CottonTextile Wet Processing: An Experimental Study. International Journal of Engineering Research and General Science Volume 3, Issue 2, 384-390

[7] K. Tamilarasan, J. Rajesh Banu, C. Jayashree, K.N. Yogalakshmi, K. Gokulakrishnan, Effect of organic loading rate on electricity generating potential of upflow anaerobic microbial fuel cell treating surgical cotton industry wastewater, Journal of Environmental Chemical Engineering 5 (2017) 1021-1026.

[8] Pengyi Cui, Xuefei Zhou, Yalei Zhang, The Feasibility Study of Cotton Pulp Wastewater Treatment with IC Anaerobic Reactor, Procedia Environmental Sciences 11 (2011) 686 - 692.

[9] S. P. Chu, The Influence of the Mineral Composition of the Medium on the Growth of Planktonic Algae, The Journal of Ecology, Vol. 30, No. 2. (Aug., 1942), pp. 284-325.

[10] A. D. Eaton, L. S. Clesceri, E. W. Rice, A. E. Greenberg and M. A. H. Franson, "Standard Methods for the Examination of Water \&
Wastewater," 21st Edition, American Public Health Association (APHA), American Water Works Association (AWWA) \& Water Environment Federation (WEF), Washington, 2005.

[11] B. Ramesh Babu, A.K. Parande, S. Raghu, and T. Prem Kumar, Cotton Textile Processing: Waste Generation and Effluent Treatment, "The Journal of Cotton Science 11:141-153 (2007)".

[12] Myra G. Borines, Rizalinda L. de Leon, Joel L. Cuello, Bioethanol production from the macroalgae Sargassum spp., Bioresource Technology 138 (2013) 22-29.

\section{AUTHORS PROFILE}

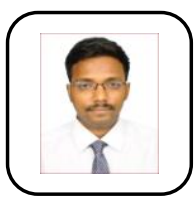

Muttupandian P. is a post graduate of chemical Engineering at National Institute of Technology Tiruchirappalli. His research interests include environmental engineering and wastewater treatment.

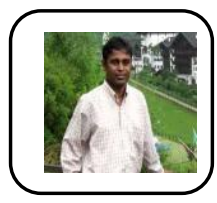

Matheswaran M. is a Associate Professor of chemical Engineering at National Institute of Technology Tiruchirappalli. He has published several papers in the field of electrochemical engineering and wastewater treatment. His h-index and i10 index are 25 and 43 respectively.

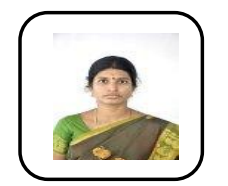

Vanitha S. is an Associate Professor in Department of Civil Engineering, Kalasalingam Academy of Research and Education. She completed her $\mathrm{PhD}$ in the area of Genetic Programming and environmental engineering. Her h-index and i10 index are 4 and 1 respectively.

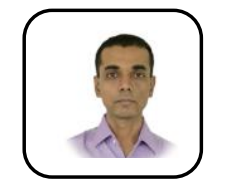

Sivapragasam C. is a Professor in Department of Civil Engineering, Kalasalingam Academy of Research and Education. He completed his $\mathrm{PhD}$ from NUS Singapore and has published several papers in the area of Artificial Intelligence in Water resources, Genetic Programming respectively. and Hydraulics. His h-index and 110 index are 11 and 12

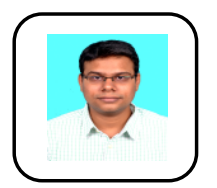

Naresh Kumar Sharma is an Associate Professor at Kalasalingam University in Department of Biotechnology. He completed his $\mathrm{PhD}$ from IIT Madras. His research interests include bioremediation and wastewater treatment. 